\title{
TIC, lectoescritura y educación en la sociedad del conocimiento
}

Aminta Ramírez Coronado

Docente Catedrática Universidad Surcolombiana amiraco@outlook.es

\section{Las transformaciones generadas por las mediaciones}

La incursión de las Nuevas Tecnologías de la Información y la comunicación (TIC) en los diferentes escenarios de la cotidianidad ha traído consigo profundas transformaciones, generadoras de oportunidades, incertidumbres y desafíos que pueden tornarse difíciles de asumir, si no se cuenta con los conocimientos, habilidades y valores requeridos.

El entorno digital que circunda la vida de niños, niñas y jóvenes, no solo ha facilitado y promovido nuevas formas de comunicación, sino que ha transformado dichas prácticas, entre ellas la lectura y la escritura convencional-analógica, que prevaleció por un prolongado periodo de la historia de la humanidad.

Cassany (2000) señala las particularidades más importantes de este mundo digitalizado, desde el que se han concebido novedosas prácticas escriturales generalizadas y arraigadas en las comunidades internautas, que propenden por una comunicación instantánea, continua, eficiente y eficaz. Dichas particularidades hacen referencia a aspectos como la instantaneidad y simultaneidad, la hipertextualidad, la intertextualidad; la aparición de nuevos géneros; la apertura del texto y la dilución del autor, entre otros.

Cada una de estas particularidades se visualizan de diversas formas en las prácticas escriturales de niños, niñas y jóvenes, nativos digitales, que con gran habilidad hacen uso permanente de tecnologías de la información y la comunicación, como el computador, el celular e internet, para comunicar, consultar, producir o reproducir información en diferentes formatos y lenguajes.

La conversación digital, primero a través de correos electrónicos, luego del chat y hoy el Whatsapp, ha generado formas escriturales propias, en los que la sintaxis se ha trastocado por la inmediatez e instantaneidad que los caracteriza; no hay una combinación rígida a de las palabras para escribir un mensaje, sino que se acude a múltiples y novedosas formas de coordinar y unir las palabras para darle un sentido y hacerse comprender, incluyendo signos, como los emoticonos, fotografías y videos que amplían la comunicación y le otorgan una significación propia a los mensajes.

A estas formas de comunicación, incluyendo los sitios Web, Cassany (2012) las ha denominado nuevos géneros, por las características particulares que presentan, que las diferencian de la formas escriturales tradicionales, derivadas de normativas impuestas por instituciones encargadas de velar por el buen uso de la lengua.

Lo anterior ha generado que la gramática convencional, se haya modificado específicamente en tres de sus niveles: el Sintáctico morfológico, el léxico semántico y el pragmático; afectaciones que visibilizan la flexibilidad que hoy por hoy y gracias al uso de estos recursos, presenta la lengua escrita.

La incorporación continua de acrónimos, abreviaturas, neologismos, combinaciones alfanuméricas, alteraciones ortográficas, supresión de grafías y en general, elementos que conforman nuevos códigos, han contribuido a que el nivel léxico semántico igualmente se haya trastocado, dando origen a la aparición de nuevas palabras y expresiones cuyos significados en la mayoría de los casos solo puede ser comprendidos por quienes conforman el grupo conversacional o la red.

En este mismo sentido, el calco semántico y la onomatopeya son constantes en estas formas de comunicación, que se generalizan y arraigan, haciendo que la lengua tanto oral como escrita evolucione y presente unas nuevas dinámicas. Cassany la ha denomina escritura Ideofenomática, asegurando que simplifica el código gráfico y explora las posibilidades significativas y lúdicas de manera creativa.

El hipertexto, tal como lo señala Cassany (2000), ha generado un estilo de escritura y lectura totalmente diferente al que venía presentando el texto analógico, porque rompe con la linealidad, atomiza el discurso en unidades pequeñas y autónomas en las que se da una 
interconexión permanente de ideas intra e intertextual con el propósito de ampliar, especificar o aclarar sobre la temática que se está tratando, llevando al escritor a prever las necesidades de los lectores, infiriendo la multiplicidad de los mismos, que pueden acceder al texto ya sea para leerlo, ampliarlo, modificarlo o cambiarlo.

Pasut (2012) afirma que cada medio, cada soporte, exige un uso específico de la lengua. En este sentido, la pragmática de la lengua escrita se ajusta al soporte digital y como lo señala Cassany, presenta unas particularidades que le caracterizan y le diferencian de la escritura analógica, que funciona desde acuerdos tácitamente establecidos y teniendo en cuenta las necesidades de los interlocutores.

La lectura en soporte digital se convierte en una experiencia de aprendizaje lúdica, personalizada, alternativa a la lectura analógica, por las características propias que le imprime este nuevo formato tecnológico: la hipertextualidad e intertextualidad, la conectividad y ubicuidad, la multimodalidad, el acceso integrado a recursos, la socialización y la criticidad entre otros.

\section{La educación y cambios}

Existen múltiples experiencias pedagógicas y didácticas en diferentes países, incluyendo el nuestros, que dan cuenta de la importancia de la implementación de las TIC en los diferentes niveles educativos. Ordenadores, tabletas, pizarras electrónicas y los mismos celulares, se convierten en recursos tecnológicos- didácticos valiosos, que facilitan y optimizan los procesos de enseñanza aprendizaje, desarrollando y fortaleciendo las competencias comunicativas, en niños, niñas y jóvenes, específicamente en lo que respecta a la lectura y escritura.

Sin embargo y pese a los muchos esfuerzos realizados tanto por los gobiernos, como por las instituciones y por los profesores en particular, aún perviven en las escuelas prácticas pedagógicas en las que no sean logrado incorporar ni los recursos, ni las metodologías que den respuesta a las necesidades de esta sociedad tecnologizada y del conocimiento. En algunos casos porque no existen los recursos tecnológicos necesarios y suficientes y en otros por la ausencia de formación del profesorado.

Al respecto, Prensky (2011) plantea tres aspectos fundamentales sobre la pedagogía y la tecnología digital. En primer lugar señala los cambios sufridos por las nuevas generaciones fuera de la escuela a consecuencia de los progresos tecnológicos de las últimas décadas y que hacen que niños, niñas y jóvenes se sientan insatisfechos frente a sus procesos formativos. En segundo lugar se refiere a la pedagogía de los centros educativos, que no responde a esas necesidades y hacen de la educación un proceso descontextualizado y aburrido "Contar y hacer exámenes". En tercer lugar, la tecnología digital está entrando a la educación, conectando a los estudiantes con su realidad y la de otras latitudes, lo que genera grandes expectativas.

Esta nueva generación, que ha tenido la oportunidad de tener acceso a estas herramientas tecnológicas, debe ser formada desde la enseñanza basada en habilidades y en la práctica "el hacer".

Por su parte Cassany (2012) en En linea_Leer y escribir en la red, realiza desde una mirada crítica e interdisciplinar una serie de cuestionamientos sobre la escritura y la lectura desde el entorno digital, basado en estudios preliminares propios y de otros investigadores del tema como Prensky.

Explica así mismos, como el uso cotidiano de estas herramientas tecnológicas ha venido generando transformaciones a nivel lingüístico y particularmente en la escritura y cómo la escuela debe reconocer estas transformaciones y emprender acciones que contribuyan a incorporar de manera pertinente estas herramientas, en aras de ofrecer procesos formativos acorde a las necesidades actuales de comunicación de los estudiantes.

\section{Lo que es posible en la educación escolarizada}

Teniendo en cuenta el impacto generado por las TIC en estos dos procesos transcendentales para el aprendizaje, como los son la lectura y la escritura, es imprescindible que tanto gobiernos, como instituciones y profesores, realicen los esfuerzos necesarios para dotar de la infraestructura requerida en las Nuevas Tecnologías de Información y la comunicación, adoptarlas como recursos didácticos, promoviendo metodologías motivantes, que partan de las realidades y necesidades de niños, niñas y jóvenes.

Las TIC como recursos didácticos, ofrecen múltiples posibilidades de uso en los procesos de enseñanza aprendizaje: la consulta en internet para ampliar saberes, lectura en línea de textos de diferentes características, edición de videos, elaboración de diapositivas, escritura e impresión de textos, comunicación en red, para socializar saberes escolares y extraescolares que hacen parte de la formación integral de los y las estudiantes, en los que la lectura y escritura se transversalizan, permitiendo de esta manera el desarrollo y fortalecimiento de las competencias comunicativas. Al respecto, Almenara (2007) en su obra Las Necesidades de las TIC en el ámbito educativo: oportunidades, riesgos y necesidades invita a la incorporación de las TIC de manera crítica, definiendo el qué, el por qué y el para qué de su incorporación y aprovechamiento de las mismas y en ese sentido reconfigurar los escenarios educativos, en los que las tecnologías sean un medio y no el fin último de la educación. Expone así mismo las posibilidades que ofrecen estas herramientas, las limitaciones que presentan, los 
mitos que se han generado en torno a las mismas y las necesidades que piden su introducción en el campo educativo.

\section{Referencias}

Almenara, J. C. (2007). Las necesidades de las TIC en el ámbito educativo: oportunidades, riesgos y necesidades. Tecnología y Comunicación Educativas, 21 (45), 5-19.

Cabero, J. y Romero, R. (2007). Diseño y producción de TIC para la formación. Barcelona, Spain: $\mathrm{UOC}$

Cassany, D. (1989). Describir el escribir: cómo se aprende a escribir. España: Paidos Ibérica

Cassany, D. (2000). De lo analógico a lo digital. El futuro de la enseñanza de la composición. Lecturay Vida, 21 (4), 6-15.

Cassany, D. (2012). En_ línea Leer y escribir en la red. Barcelona: Anagrama.

Castells, M. (1999). La era de la información: economía, sociedad y cultura, Madrid: Alianza l.

Crystal, D. y Tena, P. (2002). El lenguaje e Internet. Cambridge: University Press.

Cobo, R. y, Pardo, C. Kuklinski, H. 2007. Planeta Web 2.0. Inteligencia colectiva o medios fast food. Grup de Recerca d'Interaccions Digitals, Universitat de Vic. Flacso México. Barcelona / México DF: UVIC

Escuelas día a día: agenda de lectura y escritura en el aula. Argentina: Homo Sapiens Ediciones, 2012. ProQuest ebrary. Web.

Landow, G. P. (1991). HyperText: The Convergence of Contemporary Critical Theory and Technology Baltimore: Johns Hopkins University Press.

Landow, G. P. y Fernández, A. J. A. (2009). Hipertexto 3.0: La teoría crítica y los nuevos medios en una época de globalización. Barcelona: Paidós.

Prensky, M. (2011). Enseñar a nativos diaitales. Madrid: Ediciones SM.

Viladot, M. À. y Presas, M. À. V. (2012). Comunicación y grupos sociales. Barcelona: UOC.

UNESCO (2009). Las tecnologías de la información y la comunicación en la enseñanza: Cómo crear nuevos entornos de abierto por medio de las TTC. Manual para docentes. Montevideo: Trilce. 